\title{
The Mg and Li isotopic compositions \\ of authigenic and detrital sedimentary phases record Antarctic chemical silicate weathering across the EOT
}

\author{
DR. ADAM DAVID SPROSON ${ }^{1,2}$, TOSHIHIRO \\ YOSHIMURA $^{1}$, TAKAHIRO AZE ${ }^{2}$, SHIGEYUKI WAKAKI ${ }^{1}$, \\ TSUYOSHI ISHIKAWA ${ }^{1}$, YUSUKE YOKOYAMA ${ }^{1,2}$ AND \\ NAO OHKOUCHI ${ }^{1}$ \\ ${ }^{1}$ JAMSTEC \\ ${ }^{2}$ The University of Tokyo \\ Presenting Author: adamsproson@gmail.com
}

The Earth's climate system contains within it a series of positive feedbacks that, if future warming exceeds $2^{\circ} \mathrm{C}$, could lead to a cascade effect that would create a "Hothouse Earth" with severe negative impacts on ecosystems and human civilisation [1]. It is therefore important to understand the interplay of such feedback mechanisms if we are to better predict future climate change. On long (Myr) timescales, the hydrolysis of silicate minerals and subsequent precipitation of carbonate minerals in the ocean acts as a negative feedback within the carbon-cycle [2]. On shorter (kyr), more relevant, timescales, the subglacial weathering of fine-grained material produced during the expansion of glaciers may influence atm. $\mathrm{CO}_{2}$ and temperature [3].

The Eocene-Oligocene Transition (EOT; ca. $34 \mathrm{Ma}$ ) marks the accumulation of continental-scale ice sheets on Antarctica associated with a large surge in erosion [4, 5], of which the associated chemical silicate weathering response is not well understood. We present magnesium isotope, lithium isotope, major element and rare-earth element (REE) data for the authigenic and detrital phases of marine sediments from ODP Site 738 on the Kerguelen Plateau. During the EOT, detrital Mg and $\mathrm{Li}$ isotopes fractionate significantly as chemical weathering intensity increases due to the preferential retention of ${ }^{26} \mathrm{Mg}$ and ${ }^{7} \mathrm{Li}$ in weathering residues $[6,7]$. Authigenic $\delta^{26} \mathrm{Mg}$ and $\delta^{7} \mathrm{Li}$ values are negatively correlated, and divert towards bedrock values suggesting a switch to more congruent weathering across the EOT $[7,8]$.

The $\delta^{26} \mathrm{Mg}$ and $\delta^{7} \mathrm{Li}$ records from Site 738 display similar variation to previous lead and neodymium isotope records, and are well correlated to oxygen isotopes, suggesting continental ice sheet expansion over Antarctica led to increased silicate weathering intensity, possibly associated with further atm. $\mathrm{CO}_{2}$ drawdown and cooling indicating a positive feedback on planetary climate.

[1] Steffen et al. (2018) PNAS 115, 8252-8259. [2] Berner (2006) GCA 70, 5653-5664. [3] Kump \& Alley (1994) 46-60. [4] Basak \& Martin (2013) Nature Geo. 6, 121-124. [5] Scher et al. (2011) Geology 39, 383-386. [6] Teng et al. (2010) EPSL 300, 63-71. [7] Tipper et al. (2012) EPSL 333-334, 35-45. [8] Dellinger et al. (2015) GCA 164, 71-93. 